\title{
The Relationship between Intelligence and Executive Functions in Hispanic Patients with Mild Traumatic Brain Injury
}

\author{
Jorge A. Herrera-Pino1, Cesar E. Castellanos ${ }^{2}$ \\ ${ }^{1}$ Herbert Wertheim College of Medicine, Florida International University, Miami, FL, USA \\ ${ }^{2}$ Instituto Dominicano para el Estudio de la Salud Integral y la Psicología Aplicada, Santo Domingo, Dominican Republic \\ Email: jherreramdphd@gmail.com, cesarcastellanos1@gmail.com
}

How to cite this paper: Herrera-Pino, J. A., \& Castellanos, C. E. (2020). The Relationship between Intelligence and Executive Functions in Hispanic Patients with Mild Traumatic Brain Injury. Psychology, 11, 137-145.

https://doi.org/10.4236/psych.2020.111009

Received: October 25, 2019

Accepted: January 7, 2020

Published: January 10, 2020

Copyright $\odot 2020$ by author(s) and Scientific Research Publishing Inc. This work is licensed under the Creative Commons Attribution International License (CC BY 4.0).

http://creativecommons.org/licenses/by/4.0/

\begin{abstract}
Executive functions have been described as the "brain of the brain" and to include a variety of processes, including, but not limited to, abstraction, formulation of intentions, reasoning, formulation of strategies, monitoring their success, working memory, and the self-regulation of behavior. Executive functions have been determined to be associated with the integrity of the frontal lobes. On the other hand, intelligence has also been described in similar terms, and the concept of general intelligence, or the $\mathrm{g}$ factor has also been associated with the frontal lobes. As constructs, intelligence and executive functions have been also described as "overlapping" in many features, while maintaining a certain degree of conceptual independence. The purpose of this study was to compare the intellectual functioning of a sample of patients with mild traumatic brain injury, obtained by means of the Reynolds Intellectual Assessment Scales (RIAS), with their performance in a number of neuropsychological measures of executive functions, such as the Halstead Category Test (HCT), the Wisconsin Card Sorting Test (WCST), the Stroop Word and Color Test (SWCT), and the Trail Making Test (TMT). Pearson Product Moment Correlations were obtained between the various measures of the RIAS and the measures of executive functions (HCT, WCST, SWCT, TMT). Whereas the magnitudes of the correlations were within the moderate range, intelligence, particularly non-verbal intelligence and working memory were noted to be significantly correlated with the measures of executive functions. The conclusion was reached that intelligence and executive functions are related to each other as constructs, but yet maintain a certain degree of independence.
\end{abstract}

\section{Keywords}

Executive Functions, Intelligence, Hispanic, Mild Traumatic Brain Injury 


\section{Introduction and Literature Review}

According to Tirapu-Ustárroz et al. (2017), the term executive functions was proposed for the first time by neuropsychologist Muriel D. Lezak (1982) who defined it as mental capacities essential to carry out effective, creative, and socially accepted behavior with four components: formulation of goals (ability to generate and select the desirable states in the future), planning (selection of actions, means and sequences necessary to reach goals), development (ability to initiate, stop, maintain, and change among planned behaviors), and implementation (ability to monitor and correct behaviors).

For Lopera-Restrepo (2008), executive function refers to the directing, managerial, and guiding function of the brain. It is the "brain of the brain". In reality, the guiding or managerial function of the brain is a series of directing functions that include a variety of programming and implementing cerebral activities.

Friedman \& Miyake (2017) described executive functions as high-level cognitive processes that, through their influence on lower-level processes, allow individuals to regulate their thoughts and actions during behavior aimed at the attainment of goals.

For E. Goldberg, one of the disciples of the great teacher of neuropsychology, Alexander R. Luria, executive functions are intimately related with the integrity of the frontal lobes, to which he refers to as the "lobes of human civilization" (Goldberg, 2001). Within the model of executive functions developed by Goldberg (2009), executive functions include a series of high-level cognitive processes designed to facilitate the independent attainment of behavioral goals.

Executive functions include, in the model designed by Goldberg, processes such as abstraction, formulation of intentions, reasoning, formulation of strategies, monitoring their success, working memory, and the self-regulation of behavior (Goldberg, 2001, 2009).

The relationship between the constructs of intelligence and executive functions has raised the interest of neurocognitive researchers. The most classical and widely used definition of intelligence was proposed by David Wechsler, the author of the most frequently used instruments for the measurement of intellectual ability. According to this author, intelligence is "the aggregate or global ability to behave purposely, think rationally, and deal effectively with the environment" (Wechsler, 1958). This definition of intelligence has many elements in common with the concept of executive functions, as it is currently understood.

García-Molina et al. (2010) carried out a revision of the concepts of intelligence and executive functions with the aim of answering the question if these are the same or not. They reviewed, in the first place, the concept of the $g$ factor, within different theories of intelligence. As with the concept of executive functions, the $\mathrm{g}$ factor has been closely related to the functioning of the pre-frontal cortex and is viewed as a mechanism responsible for the coordination and control of cognitive processes involved in problem-solving. The intellectual processes that were estimated to have a closer relationship to executive functions are those 
related to fluid intelligence.

On the other hand, these authors concluded that the diversity of theoretical views of both intelligence and executive functions, as well as the absence of instruments to assess both processes in a comprehensive manner, makes it difficult to answer the question if both constructs represent or not the same reality. According to these authors, in regards to this question: "The studies described in this article offer different answers, being the hypothesis that has greater acceptance the one that considers intelligence and exectutive functions as overlapping in certain aspects, but not in others (p. 744)".

\section{Purpose of This Study}

The purpose of this study is to determine the relationship that exists between intelligence, measured by means of the Reynolds Intellectual Assessment Scales (RIAS; Reynolds \& Kamphaus, 2009) and executive functions assessed by means of the Halstead Category Test (HCT; Halstead, 1947; Reitan \& Wolfson, 1993), the Wisconsin Card Sorting Test (WCST; Berg, 1948; Grant \& Berg, 1948; Heaton et al., 1993, 2009), the Stroop Word and Color Test (SWCT; Golden, 2001) and the Trail Making Test (TMT; Reitan, 1958; Reitan \& Wolfson, 1993), as well as to determine which component or components of intellectual functioning, that is, crystallized intelligence, fluid intelligence, or working memory are more closely related with the construct of executive functions.

\section{Ethical Considerations}

This study was authorized by the Institutional Review Board of the Neurobehavioral Institute of Miami as an archival research.

\section{Methodology}

\subsection{Participants}

The participants of this study were 39 Hispanic patients referred for neuropsychological evaluation by their treating neurologists to the Neurobehavioral Institute of Miami for neuropsychological evaluation with a history of having sustained a closed head injury resulting in a mild traumatic brain injury (mTBI), with alterations in consciousness for less than one hour, as well as having retrograde amnesia also for less than one hour. The mean age of this sample was 41 years, with a standard deviation (sd) of 17.34, with values between 13 and 77 years and $56 \%$ being women. The major cause of $\mathrm{mTBI}$ in this sample was motor vehicle accidents (20). Patients with mTBI resulting from falls and physical assaults were also included.

The distribution of the educational level of the sample was as follows: $38 \%$ had a college level education, $26 \%$ had a technical level education, and $23 \%$ had a high school level education. The remaining $10 \%$ had an elementary level or middle school level education. All the patients had negative neurological examinations, as well as negative electroencephalograms (EEG), computerized axial to- 
mographies (CAT Scan), and magnetic resonances (MRI).

\subsection{Procedures}

All patients were administered a battery of neuropsychological instruments, which included a measure of intelligence, the Reynolds Intellectual Assessment Scales, as well as a number of measures of executive functions, among which were a computerized version of the Halstead Category Test, a computerized version of the Wisconsin Card Sorting Test, the Stroop Word and Color Test, and the Trail Making Test.

The variables selected for each of these instruments were as follows. For the Reynolds Intellectual Assessment Scales the scaled scores for the Verbal Intelligence Index (VIX), a measure of crystallized intelligence acquired through experience and education, the Non-Verbal Intelligence Index (NIX), a measure of fluid intelligence, including problem solving and abstracting ability without the use of language, the Composite Intelligence Index (CIX), and the Composite Memory Index (CMX), a measure of working memory, were selected.

The variable selected for the Halstead Category Test was the number of errors made (ERR). For the Wisconsin Card Sorting Test, the number of categories attained (CAT) and the number of perseveration errors (PE) made were selected. For the Stroop Word and Color Test, the number of correct responses made in the word (STW), color (STC), and color-word (STCW) conditions of administration were selected. For the Trail Making Test, the time required to complete Part A (TMA) and Part B (TMB) were selected as variables. All instruments were administered to the participants in Spanish, as this was their language preference.

In order to determine if the participants had made an appropriate effort in the performance of the instruments included in the neuropsychological battery administered to them, they were administered two instruments designed for that purpose, the Test of Memory Malingering (Tombaugh, 2011) and the Rey 15-Item Memory Test (Strauss, Sherman, \& Spreen, 2006). Only participants with scores in these two instruments that reflected the application of appropriate effort were included in this study.

The instruments selected for the assessment of executive functions in this study have a solid trajectory of being sensitive to lesions in the frontal lobes, particularly in patients with mild traumatic brain injury. Relative to the Halstead Category Test the reader is referred to the following publications: Choca et al. (1997) and Herrera Pino, Salcedo Samper, \& Jubiz Bassi (2008). In order to determine the ability of the Wisconsin Card Sorting Test to assess executive functions mediated by the frontal lobes, the reader is referred to the following works: de Assis Faria et al. (2015) and Herrera Pino, Salcedo Samper, \& Jubiz Bassi (2019c).

The ability to assess executive functions mediated by the frontal lobes by the Stroop Word and Color Test was explored in the following publications: de Assis Faria et al. (2015) and Herrera Pino et al. (2019a). The assessment of executive 
functions by means of the Trail Making Test has been explored in the following publications: de Assis Faria et al. (2015) and Herrera Pino, Jubiz Bassi, \& Salcedo Samper (2019b).

\subsection{Statistical Analysis}

The SPSS.20 program was used to analyze the data in terms of frequencies, descriptive statistics, and correlations. The variables of the Reynolds Intellectual Assessment Scales were correlated with the variables of the Halstead Category Test, the Wisconsin Card Sorting Test, the Stroop Word and Color Test, and the Trail Making Test. Pearson Product Moment Coefficients of Correlation were used for the analysis of the results.

\section{Results}

The means and standard deviations of the four indices of the RIAS can be found in Table 1. The mean score of the Verbal Intelligence Index (VIX) was 82.74, with a standard deviation (sd) of 15.96. The corresponding value for the Nonverbal Intelligence Index (NIX) was 88.23 ( $s d=13.09$ ), with a mean value of $83.31(\mathrm{sd}=14.21)$ for the Composite Intelligence Index (CIX). The mean Composite Memory Index $(\mathrm{CMX})$ was $91.10(\mathrm{sd}=16.29)$.

The mean number of errors (ERR) made in the Halstead Category Test (HCT) was $74.00(\mathrm{sd}=35.95)$. The mean number of categories achieved (CAT) in the Wisconsin Card Sorting Test (WCST) was $4.21(\mathrm{sd}=2.04)$, and the mean number of perseveration errors $(\mathrm{PE})$ made was $26.28(\mathrm{sd}=17.61)($ See Table 2$)$.

Table 1. Means and standard deviations for the RIAS variables.

\begin{tabular}{rcc}
\hline & Mean & Standard Deviation \\
\hline RIAS VIX & 82.74 & 15.96 \\
RIAS NIX & 88.23 & 13.09 \\
RIAS CIX & 83.31 & 14.21 \\
RIAS CMX & 91.10 & 16.29
\end{tabular}

Table 2. Means and standard deviations for the executive functions variables.

\begin{tabular}{rcc}
\hline & Mean & Standard Deviation \\
\hline HCT ERR & 74.00 & 35.95 \\
WCST CAT & 4.21 & 2.04 \\
WCST PE & 26.28 & 17.61 \\
SWCT STW & 75.44 & 21.59 \\
SWCT STC & 56.87 & 15.28 \\
SWCT STCW & 32.33 & 12.77 \\
TMT TMA & 52.13 & 29.63 \\
TMT TMB & 140.36 & 83.45 \\
\hline
\end{tabular}


The mean number of correct responses made for the word administration (STW) of the Stroop Word Color Test (SWCT) was 75.44 (sd = 21.59), for the color condition of administration (STC) the corresponding value was 56.87 ( $\mathrm{sd}=$ 15.28), and for the color-word condition (STCW) was 32.33 (sd =12.17). The mean time for the completion of Part A (TMA) of the Trail Making Test (TMT) was 52.13 seconds $(\mathrm{sd}=29.63)$ and for the completion of Part B $(\mathrm{TMB})$ was 140.36 seconds $(\mathrm{sd}=83.45)$ (See Table 2$)$.

Following, the Pearson Product Moment Coefficients of Correlation between the variables of the Reynolds Intellectual Assessment Scales and the measures of executive functions selected for this study are presented (See Table 3).

The Non-verbal Intelligence Index (NIX) showed a positive, moderate, and significant correlation with the number of categories attained (CAT) of the Wisconsin Card Sorting Test ( $r=0.487, p=0.001)$, while the correlation between this variable and the number of errors of perseveration (EP) was negative, moderate, and also significant $(r=-0.425, p=004)$.

The NIX was also negatively, moderately, and significantly correlated with the number of errors (ERR) of the Halstead Category Test $(r=-0.406, p=0.005)$. The NIX also showed a negative, moderate, and significant correlation with the time taken to complete Part A (TMA) of the Trail Making Test ( $\mathrm{r}=-0.541, p=$ $000)$, as well as with the time required to complete Part B (TMB) of this instrument $(r=-0.492, p=0.001)$. The correlations between the NIX and the three conditions of administration of the Stroop Word and Color Test were positive, moderate, and significant: word (STW) $(\mathrm{r}=0.524, p=0.000)$, color $(\mathrm{STC})(\mathrm{r}=$ 0.597, $p=000)$, and color-word (STCW) $(\mathrm{r}=0.45, p=002)$.

The correlation between the Composite Intelligence Index (CIX) and the number of categories attained (CAT) in the Wisconsin Card Sorting Test was also positive, moderate, and significant $(r=0.36, p=0.012)$, whereas the number of perseveration errors (PE) showed a correlation also moderate and significant, but negative, with the CIX ( $\mathrm{r}=-0.459, p=0.002)$, as well as with the number of errors (ERR) made in the Halstead Category Test $(r=-0.446, p=$ $0.002)$.

Table 3. Correlations between the intelligence and executive functions variables.

\begin{tabular}{ccccc}
\hline & RIAS VIX & RIAS NIX & RIAS CIX & RIAS CMX \\
\hline HCT ERR & -0.396 & -0.406 & -0.446 & -0.295 \\
WCST CAT & 0.150 & 0.487 & 0.360 & 0.293 \\
WCST PE & 0.388 & -0.425 & -0.459 & -0.141 \\
SWCT STW & 0.143 & 0.524 & 0.372 & 0.295 \\
SWCT STC & 0.311 & 0.597 & 0.533 & 0.656 \\
SWCT STCW & 0.301 & 0.450 & 0.454 & 0.511 \\
TMT TMA & -0.153 & -0.541 & -0.397 & -0.485 \\
TMT TMB & -0.290 & -0.492 & -0.461 & -0.546 \\
\hline
\end{tabular}


The same was observed with the time required to complete Part A (TMA) of the Trail Making Test $(\mathrm{r}=-0.397, p=0.006)$, as well as with Part B (TMB) of this instrument $(\mathrm{r}=-0.461, p=0.002)$. As with the correlations with the NIX, the correlations between the CIX and the three conditions of administration of the Stroop Word and Color Test were also positive, moderate, and significant: word (STW) $(r=0.372, p=0.01)$, color (STC) $(r=0.533, p=0.000)$ and color-word (STCW) $(\mathrm{r}=0.454, \mathrm{p}=0.002)$.

The Composite Memory Index (CMX) showed moderate, negative, and significant correlations with the time required to complete Part A (TMA) of the Trail Making Test $(\mathrm{r}=-0.485, p=0.001)$, as well as with the time required to complete Part B (TMB) $(r=-0.546, p=0.000)$. This measure also showed positive, relatively high, and significant correlations with the color (STC) condition of administration of the Stroop Word and Color Test $(\mathrm{r}=0.656, p=0.000)$, and the color-word condition of administration (STCW) $(\mathrm{r}=0.511, p=0.000)$.

\section{Conclusion}

The findings of this research study showed that the constructs of intelligence and executive functions have a statistically significant relationship, although moderate in magnitude. In particular, fluid intelligence and working memory showed the highest correlations between these two constructs. The moderate magnitude of the correlations obtained supports the notion that, although intelligence and executive functions are related, they nonetheless maintain a certain independence.

On the other hand, crystallized intelligence, which represents the level of knowledge acquired by means of experience and education, did not show statistically significant correlations with executive functions. It is quite interesting to note that crystallized intelligence is closely related to another important construct, cognitive reserve. It would be interesting that other research studies explore the relationship between cognitive reserve and executive functions.

\section{Conflicts of Interest}

The authors declare no conflicts of interest regarding the publication of this paper.

\section{References}

Berg, E. A. (1948). A Simple Objective Technique for Measuring Flexibility of Thinking. Journal of General Psychology, 39, 15-22. https://doi.org/10.1080/00221309.1948.9918159

Choca, I. P., Laatsch, I., Wetzel, I., \& Agresti, A. (1997). The Halstead Category Test: A Fifty-Year Perspective. Neuropsychology Review, 7, 61-75. https://doi.org/10.1023/B:NERV.0000005944.98635.16

de Assis Faria, C., Dias Alves, E. V., \& Charchat-Fichman, H. (2015). The Most Frequently Used Tests for Assessing Executive Functions in Aging. Dementia \& Neuropsycholia, 9, 149-155. https://doi.org/10.1590/1980-57642015DN92000009 
Friedman, N. P., \& Miyake, A. (2017). Unity and Diversity of Executive Functions: Individual Differences as a Window on Cognitive Structure. Cortex, 86, 186-204. https://doi.org/10.1016/j.cortex.2016.04.023

García-Molina, A., Tirapu-Ustárroz, J., Luna-Lario, P., Ibáñez, J., \& Duque, P. (2010). ¿Son lo mismo inteligencia y funciones ejecutivas? Revista de Neurología, 50, 738-746. https://doi.org/10.33588/rn.5012.2009713

Goldberg, E. (2001). The Executive Brain: Frontal Lobes and the Civilized Mind. New York: Oxford University Press.

Goldberg, E. (2009). The New Executive Brain: The Frontal Lobes in a Complex World. New York: Oxford University Press.

Golden, C.J. (2001). STROOP: Test de Colores y Palabras. Madrid, ES: TEA Ediciones, S.A.

Grant, D. A., \& Berg, E. (1948). A Behavioral Analysis of Degree of Reinforcement and Ease of Shifting to New Responses in a Weigl-Type Card Sorting Problem. Journal of Experimental Psychology, 38, 404-411. https://doi.org/10.1037/h0059831

Halstead, W. C. (1947). Brain and Intelligence. Chicago, IL: University of Chicago Press.

Heaton, R. K., Chelune, G. J., Talley, J. L., Kay, G. G., \& Curtiss (2009). Test de Clasificación de Tarjetas de Wisconsin manual (2a Edición). Madrid: TEA Ediciones, S.A.

Heaton, R. K., Chelune, G. J., Talley, J. L., Kay, G. G., \& Curtiss (1993). Wisconsin Card Sorting Test Manual (Revised and Expanded). Odessa, FL: Psychological Assessment Resources.

Herrera Pino, J. A., Castellanos Araujo, C. E., Salcedo Samper, G. P., \& Jubiz Bassi, N. S. (2019a). Interpretación neuropsicológica del Test de Palabras y Colores de Stroop (2da. Edición). Coral Gables, FL: Interamerican Academy of Applied Cognitive Neuroscience.

Herrera Pino, J. A., Jubiz Bassi, N. S., \& Salcedo Samper, G. P. (2019b). Interpretación neuropsicológica del Test de Trazados (Rastreo) de Halstead-Reitan (2da. Edición). Coral Gables, FL: Interamerican Academy of Applied Cognitive Neuroscience.

Herrera Pino, J. A., Salcedo Samper, G. P., \& Jubiz Bassi, N. S. (2019c). Interpretación neuropsicológica del Test de Clasificación de Tarjetas de Wisconsin (2da. Edición). Coral Gables, FL: Interamerican Academy of Applied Cognitive Neuroscience.

Herrera Pino, J. A., Salcedo Samper, G. P., \& Jubiz Bassi, N. S. (2008). Interpretación neuropsicológica del Test de Categorías de Halstead. Coral Gables, FL: Interamerican Academy of Applied Cognitive Neuroscience.

Lezak, M. D. (1982). The Problem of Assessing Executive Functions. International Journal of Psychology, 17, 281-297. https://doi.org/10.1080/00207598208247445

Lopera-Restrepo, F. (2008). Funciones ejecutivas: Aspectos clínicos. Revista Neuropsicología, Neuropsiquiatría y Neurociencias, 8, 59-76.

Reitan, R. M. (1958). Validity of the Trail Making Test as an Indicator of Organic Brain Damage. Perceptual \& Motor Skills, 8, 271-276.

https://doi.org/10.2466/pms.1958.8.3.271

Reitan, R. M., \& Wolfson, D. (1993). The Halstead-Reitan Neuropsychological Test Battery: Theory and Clinical Interpretation (2nd ed.). Tucson, AZ: Neuropsychology Press.

Reynolds, C. R., \& Kamphaus, R. W. (2009). RIAS. Escalas de Inteligencia de Reynolds. Madrid: TEA Ediciones, S.A.

Strauss, E., Sherman, E. M. S., \& Spreen, O. (2006). A Compendium of Neuropsychological Tests: Administration, Norms, and Commentary(3rd ed.). New York: Oxford Uni- 
versity Press.

Tirapu-Ustárroz, J., Cordero-Andrés, P., Luna-Lario, P., \& Hernáez-Goñi, P. (2017). Propuesta de un modelo de funciones ejecutivas basado en análisis factoriales. Revista de Neurología, 64, 75-84. https://doi.org/10.33588/rn.6402.2016227

Tombaugh, T. (2011). TOMM Test de Simulación de Problemas de Memoria. Madrid, ES: TEA Ediciones, S.A.

Wechsler, D. (1958). The Measurement and Appraisal of Adult Intelligence (4th ed.). Baltimore, MD: Williams \& Wilkins. https://doi.org/10.1037/11167-000 